\title{
Distribution of arterial lesions and collateral pathways in the pulmonary hypertension of congenital heart disease: a computer aided reconstruction study
}

\author{
Gen-ya Yaginuma, Hitoshi Mohri, Tohru Takahashi
}

\begin{abstract}
Three dimensional computer aided reconstructions of pulmonary vessels were used to investigate the distribution of vascular changes and the formation of collateral channels in 11 patients with congenital heart disease. In the patients with less severe grades of hypertensive pulmonary vascular disease obstructive changes were unevenly distributed, whereas in those with disease of grade 4 or more distribution became more even. Plexiform lesions occurred rather more frequently in supernumerary arteries arising laterally from a large parent vessel, whereas cellular or fibrous intimal thickening tended to affect dichotomous branches at the periphery. Hypertensive changes were confined to arteries of 100-150 $\mu \mathrm{m}$ diameter running along the necks of acini. Various types of collateral channels were found. In particular, the reconstructions suggest that pulmonary arterial blood at high pressure could flow into bronchial arteries via proximal bronchopulmonary arterial anastomoses, and thence by way of dilatation lesions to the alveolar capillaries.
\end{abstract}

In congenital heart disease associated with a large left to right shunt the pulmonary arteries undergo a series of changes that may be graded according to their severity. Pulmonary vascular resistance increases in parallel. Grade 1 and 2 disease is characterised by medial hypertrophy and intimal cellular proliferation respectively and is reversible. Later, with the development of intimal fibrosis, plexiform and dilatation lesions and necrotising arteritis (grade 3-6 disease), the damage to the pulmonary vascular bed becomes irreversible. ${ }^{1-3}$

Although the morphology of these changes is well documented, ${ }^{1-3}$ their pattern of distribution has not been established. In some patients it appears to be patchy, whereas in others the greater part of the vasculature seems to be affected. Clearly, if there is uniform obstruction of the pulmonary arterial tree, blood flow could not be maintained without the development of collateral vessels; but what form these collaterals take and where they are situated is uncertain. It has been suspected that dilatation lesions (the atten- uated, vein like vessels that develop in grade 5 disease $^{2}$ ) function in this way, ${ }^{3-4}$ and they have also been shown to communicate with the distal channels of plexiform lesions. ${ }^{4-5}$ The exact relation between dilatation lesions and the overall vasculature of the lung, however, is complex and poorly understood. ${ }^{24-7}$

These problems cannot be resolved by routine histological techniques or by conventional stereology. ${ }^{8}$ A computer assisted three dimensional reconstruction was therefore undertaken to investigate the distribution of the various lesions, the formation of collateral vessels, and the consequent reorganisation of the pulmonary circulation.

\section{Methods}

Lungs from 11 patients with congenital cardiac malformation were studied (table 1). Lungs obtained at necropsy from two patients were judged to have grade 2 or 3 changes. The remaining nine patients had at least grade 4 disease: specimens were obtained in seven of these cases at necropsy and in two by biopsy. Two lungs, obtained at necropsy, with no cardiac or pulmonary disease were used as controls. In the lungs obtained at necropsy a specimen was chosen at random from several taken from the right lung, and in the biopsy specimens a single sample was obtained from the upper lobe of the left lung. The sectional areas of the blocks from the necropsies varied from 5 to $7 \mathrm{~cm}^{2}$. All specimens were fixed in formalin and embedded in celloidin-paraffin; about 1000 serial sections $4 \mu \mathrm{m}$ thick were

Table 1 Details of the cases examined

\begin{tabular}{llll}
\hline Case No & $\begin{array}{l}\text { Age }(y), \\
\text { sex }\end{array}$ & $\begin{array}{l}\text { Clinical } \\
\text { diagnosis }\end{array}$ & Grade \\
\hline $1^{\star}$ & $44, \mathrm{~F}$ & ASD & 4 \\
2 & $74, \mathrm{~F}$ & ASD & 4 \\
3 & $2, \mathrm{M}$ & TAC & 4 \\
4 & $2, \mathrm{M}$ & VSD + ASD & 2 \\
5 & $3, \mathrm{~F}$ & VSD & 4 \\
6 & $12, \mathrm{M}$ & VSD & 4 \\
7 & $1, \mathrm{M}$ & TGA (type I) & 3 \\
8 & $2, \mathrm{M}$ & TGA (type I) & 4 \\
9 & $2, \mathrm{M}$ & TGA (type II) & 4 \\
10 & $8, \mathrm{M}$ & TGA (type II) & 4 \\
$11^{\star}$ & $38, \mathrm{~F}$ & TAPVC & 4 \\
\hline
\end{tabular}

$\star$ Biopsy material.

ASD-atrial septal defect; TAC-truncus arteriosus $\begin{array}{llr}\text { ASD-atrial septal defect; TAC-truncus } & \text { arteriosus } \\ \text { communis; } & \text { VSD-ventricular } & \text { septal }\end{array}$ TGA-complete transposition of the great arteries; TAPVC-total anomalous pulmonary venous connection. 


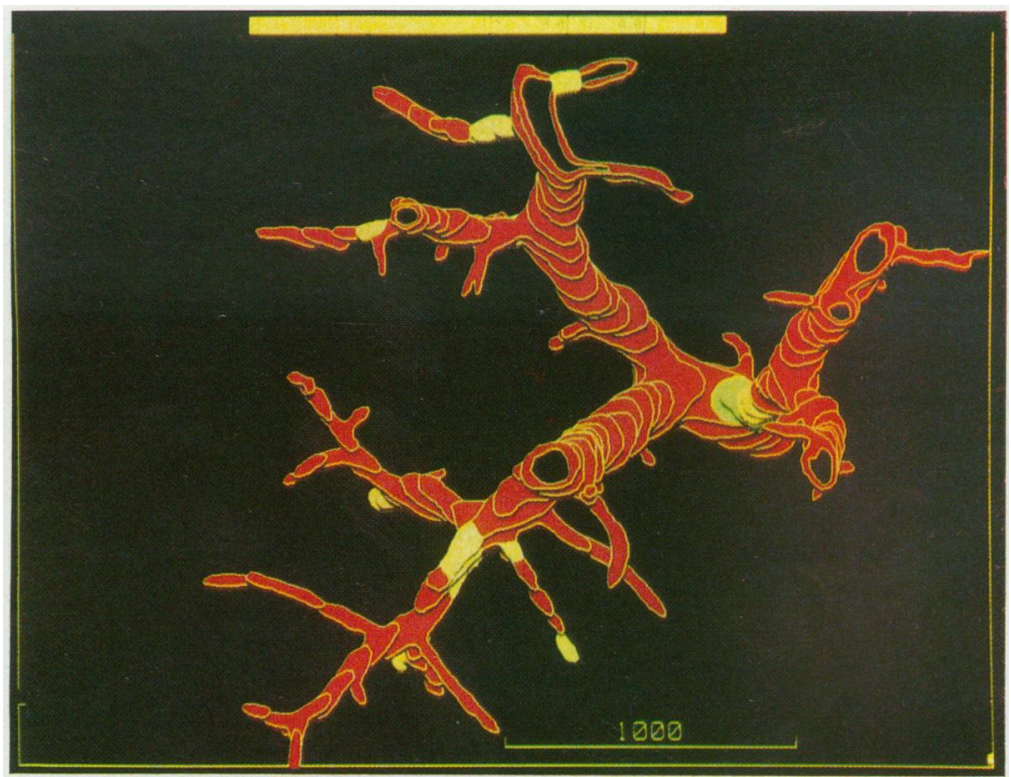

Figure 1 Distal pulmonary arteries in grade 3 hypertensive pulmonary vascular disease. Intimal lesions (yellow) lie just distal to the bifurcations; some vessels remain patent.

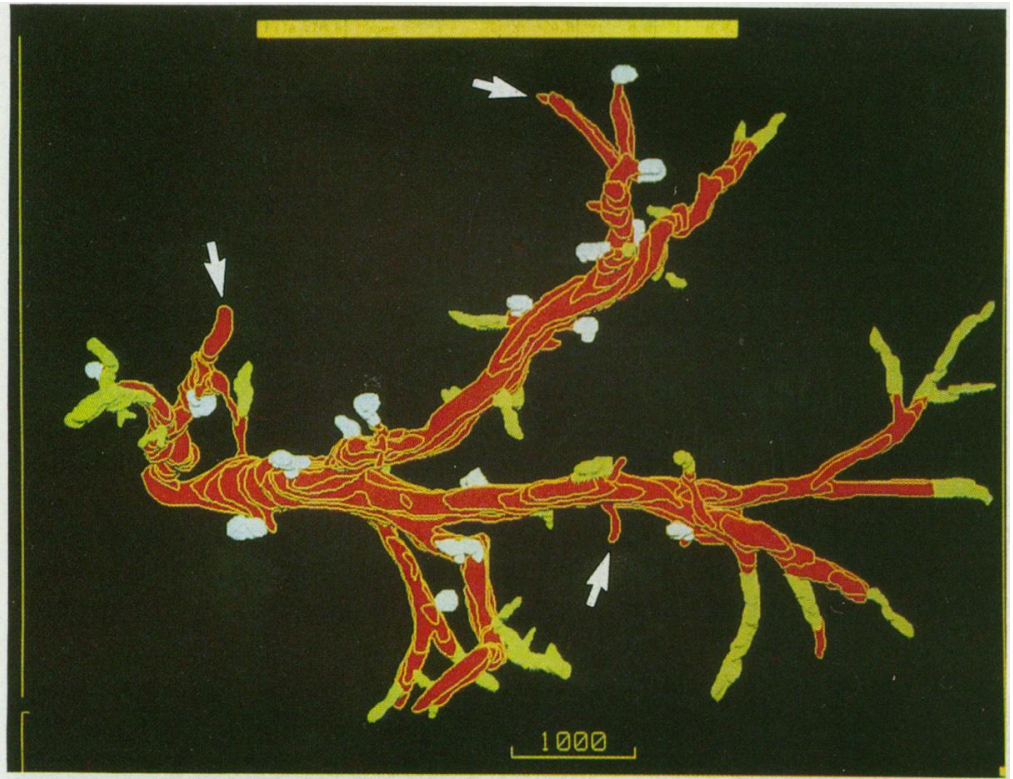

Figure 2 Distal pulmonary arteries in grade 4 hypertensive pulmonary vascular disease. Plexiform lesions (blue) occur in small side branches arising from large parent arteries. Intimal lesions (light green) are located in peripheral dichotomous branches. $A$ few patent vessels remain (arrows).

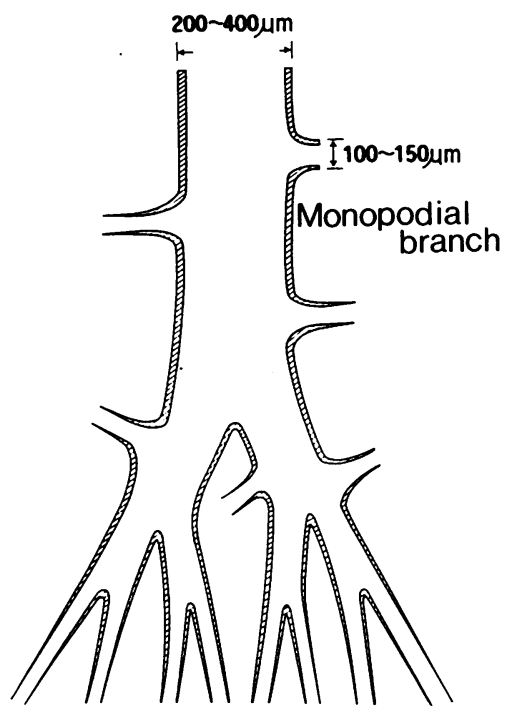

Dichotomous branch

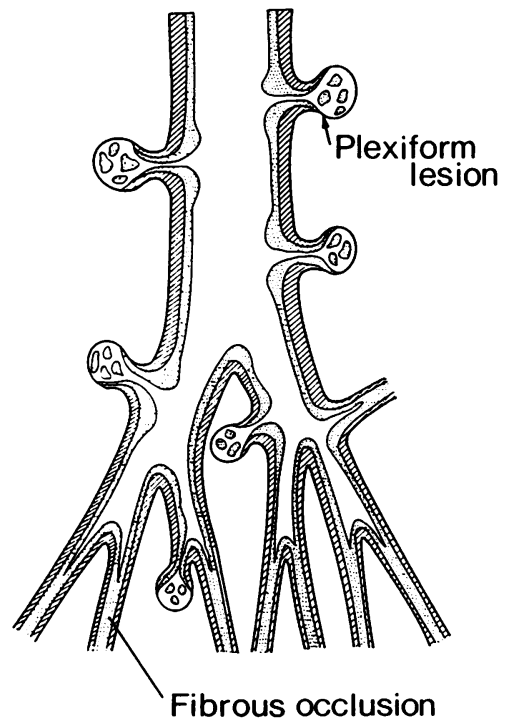

Fibrous occlusion
Figure 3 Schematic drawing illustrating the distribution of arterial changes. Plexiform lesions occur in side twigs arising from a parent artery 2-400 $\mu \mathrm{m}$ in diameter, whereas fibrous or cellular intimal thickening usually develops in dichotomous branches at the periphery. prepared from each block and stained by the elastica-Goldner method.

An area from each set of serial sections was magnified and projected on to a sheet of tracing paper by means of a profile projector (Nikon, model V-16C); the outlines of the arterial and venous vessels and airways in the area were then delineated. This process was repeated at intervals of 5-10 sections until a consecutive series of 100-200 traces had been prepared. A magnification of 20 or 50 was used for studying the distribution of arterial lesions and collateral vessels and 200 for examining the internal structure of plexiform lesions.

The traces were then integrated into a three dimensional picture by means of a computer system developed in our department with the cooperation of the Olympus Optical Company. ${ }^{910}$ This system enables a three dimensional image to be created at any angle of rotation around the $x, y$, and $z$ axes, thus allowing the operator to obtain the desired view.

\section{Results}

THE DISTRIBUTION OF ARTERIAL LESIONS

In the lungs showing grade 3 disease focal stenoses produced by cellular or fibrous intimal thickening were found only in arterial vessels $100-150 \mu \mathrm{m}$ in diameter, close to their origins from parent vessels (fig 1). Only part of the vascular bed was affected, many vessels remaining patent. In more advanced cases (fig 2) plexiform lesions were seen in small arterial vessels $100-150 \mu \mathrm{m}$ in diameter-vessels we have named acinar arteries, as arteries of this size run along the necks of the acini. Intimal thickening was rather more prevalent in peripheral branches dividing by symmetrical regular dichotomy, whereas plexiform lesions tended to occur in supernumerary arteries arising from disproportionately large parent vessels (figs 1-3). In cases 3,6,8, and 9, where a comparatively large volume of tissue was available, $57.5 \%$ of plexiform lesions arose in supernumerary vessels and $59.3 \%$ of intimal thickenings in dichotomous branches (table 2).

The degree to which the vascular bed was narrowed varied in the advanced cases. In case 11 (fig 2), for instance, about $10 \%$ of the acinar arteries remained patent, whereas in case 10 obstruction appeared to be complete.

\section{DEVELOPMENT OF BRONCHOPULMONARY ARTERIAL COLLATERALS}

Reconstructions from the nine patients with grade 4 lesions showed various ways in which dilatation lesions communicate with vessels in and around the acinus (figs 4-6).

Usually, a dilatation lesion started distal to an obstructive focus, ran in interacinar tissues towards a pulmonary vein radicle, and then dissipated in the alveolar capillaries in the perivenous zone of the acinus (figs 4 and 5). Other components of dilatation lesions lay in peribronchiolar tissues, and then joined peripheral segments of bronchial arteries running parallel to a terminal or respiratory bronchiole (figs 4 and 6). A small portion also approached the parent pulmonary artery and joined its vasa vasorum, which are also derived from the bronchial arterial tree (figs 4 and 6 ). 
Table 2 Classification ${ }^{\star}$ of 40 plexiform lesions and 59 stenotic intimal thickenings in cases 3 , 6,8 , and 9 according to whether they arose from supernumerary or dichotomous arteries.

\begin{tabular}{|c|c|c|c|c|}
\hline & Supernumerary & Dichotomous & Ambiguous & Total \\
\hline $\begin{array}{l}\text { No }\left({ }^{0}{ }_{0}\right) \text { of: } \\
\text { plexiform lesions } \\
\text { intimal thickenings }\end{array}$ & $\begin{array}{l}23(57 \cdot 5) \\
21(35 \cdot 6)\end{array}$ & $\begin{array}{l}11(27 \cdot 5) \\
35(59 \cdot 3)\end{array}$ & $\begin{array}{l}6(15) \\
3(5 \cdot 1)\end{array}$ & $\begin{array}{l}40 \\
59\end{array}$ \\
\hline
\end{tabular}

^Arteries where distinction was not possible were classified as "ambiguous."

At a prestenotic level, supernumerary vessels about $150 \mu \mathrm{m}$ in diameter arose from pulmonary arteries $1-2 \mathrm{~mm}$ in diameter (fig 7). These connecting vessels, which were free from any hypertensive changes, communicated with the arterial plexus of the subsegmental bronchi (figs 6 and 7).

\section{Discussion}

The results of this investigation show that obstruction of the pulmonary vascular bed is only partial in grade 2 and 3 disease, and that even in grade 4 disease there is still some variation in the distribution of the lesions; if all acinar arteries are affected, circulation appears to be mainly if not exclusively via newly formed collateral vessels. Moreover, the type of lesion that develops seems to depend to some extent on its site in the vascular tree. The branching pattern of the pulmonary arteries is basically dichotomous, with supernumerary twigs also arising laterally from comparatively large vessels. ${ }^{112}$ Although the lesions develop in arteries of about the same calibre, plexiform lesions develop rather more frequently in supernumerary twigs, whereas intimal thickening tends to affect peripheral, dichotomously branching segments. This pattern may reflect a difference in haemodynamic conditions prevailing at these sites, such as pressure load or shear stress.

Grade 2 and 3 changes were said to affect muscular pulmonary arteries less than $300 \mu \mathrm{m}$ in diameter ${ }^{3}$; but our reconstructions indicate that all changes, including plexiform lesions, are located exclusively in vessels $100-150 \mu \mathrm{m}$ in diameter. Vessels of this size run along the neck of the acinus, where functionally hypoxic vasoconstriction is said to occur. ${ }^{1314}$ The development of plexiform lesions has been explained on the basis of recurrent vasoconstriction that damages medial smooth muscle, causing the affected segment to dilate into a microaneurysm. This "spasmogenic theory"15 would be further strengthened if the acinar arteries were shown to have a role in regulating pulmonary blood flow. Possibly at the neck of the acinus the regulatory mechanism for blood flow coexists with that for acinar ventilation.

Dilatation lesions have been claimed to arise just proximal to an obstruction but no such prestenotic origin was seen in our material. Instead they were always downstream of a plexiform lesion or an intimal thickening. Plexiform and dilatation lesions have also been interpreted as altered pulmonary arteriovenous anastomoses ${ }^{16}$ or bronchopulmonary arterial anastomoses, ${ }^{17}$ but in our material dilatation lesions always arose in previously normal arterioles. On the other hand, their previously reported connection with small interacinar arterioles, ${ }^{5-7}$ bronchial arteries, and radicles of pulmonary veins ${ }^{45}$ has been confirmed by this study. In addition, bronchopulmonary arterial anastomoses have been found for the first time in proximal pulmonary arteries.

In congenital heart diseases associated with a low pulmonary blood flow, and also in dogs after experimental ligation of the pulmonary
Figure 4 Lung vasculature in advanced disease. Arising in close association with a plexiform lesion (left), dilatation lesions (dar blue) extend towards alveolar capillaries, whil others communicate with terminal bronchial arteries running along a bronchiole $(A)$ or with those forming the vasa vasorum of $a$ pulmonary artery $(B)$. The arteriole with "intimal thickening" is severely obstructed by grade 3 disease.

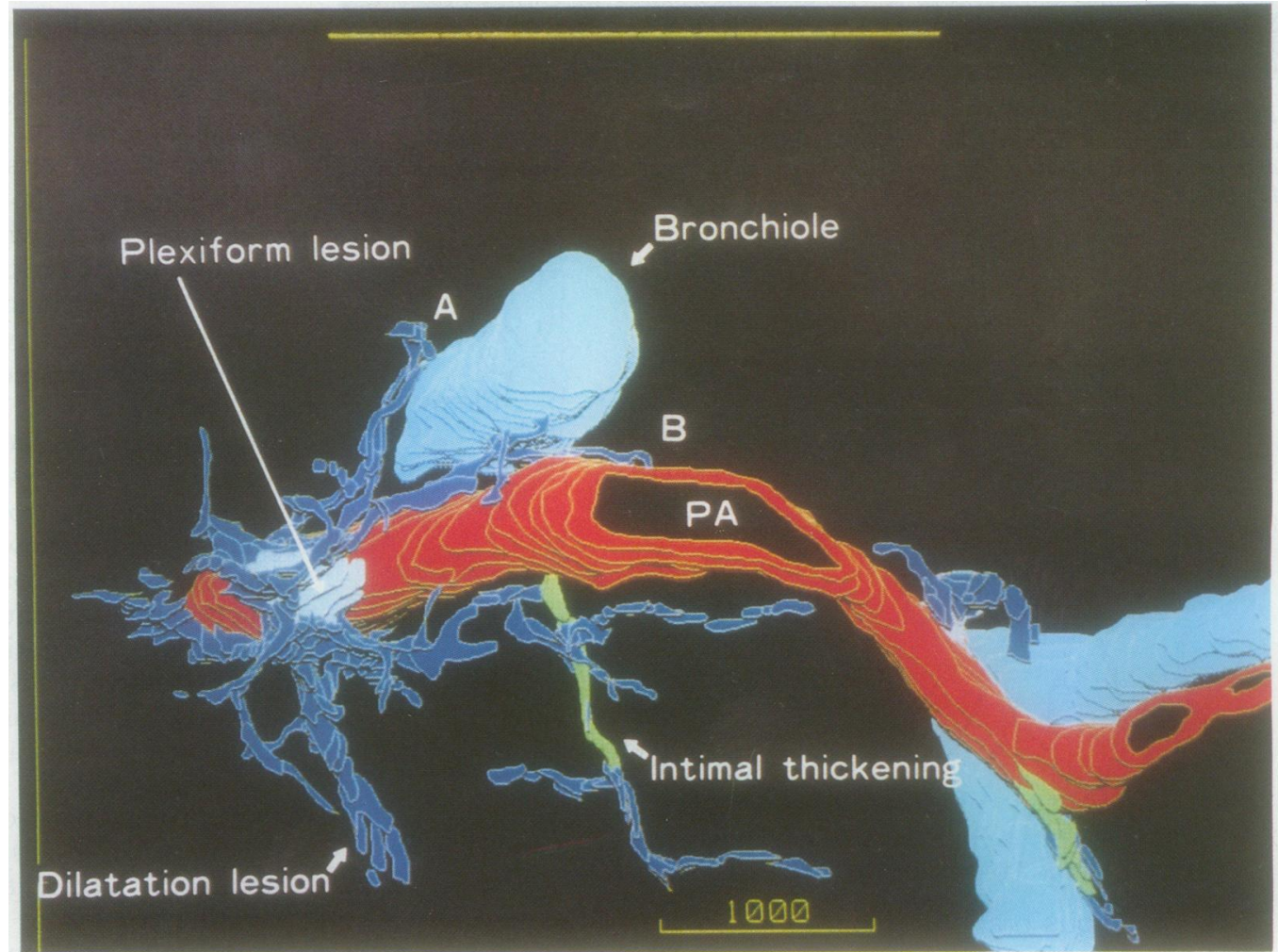




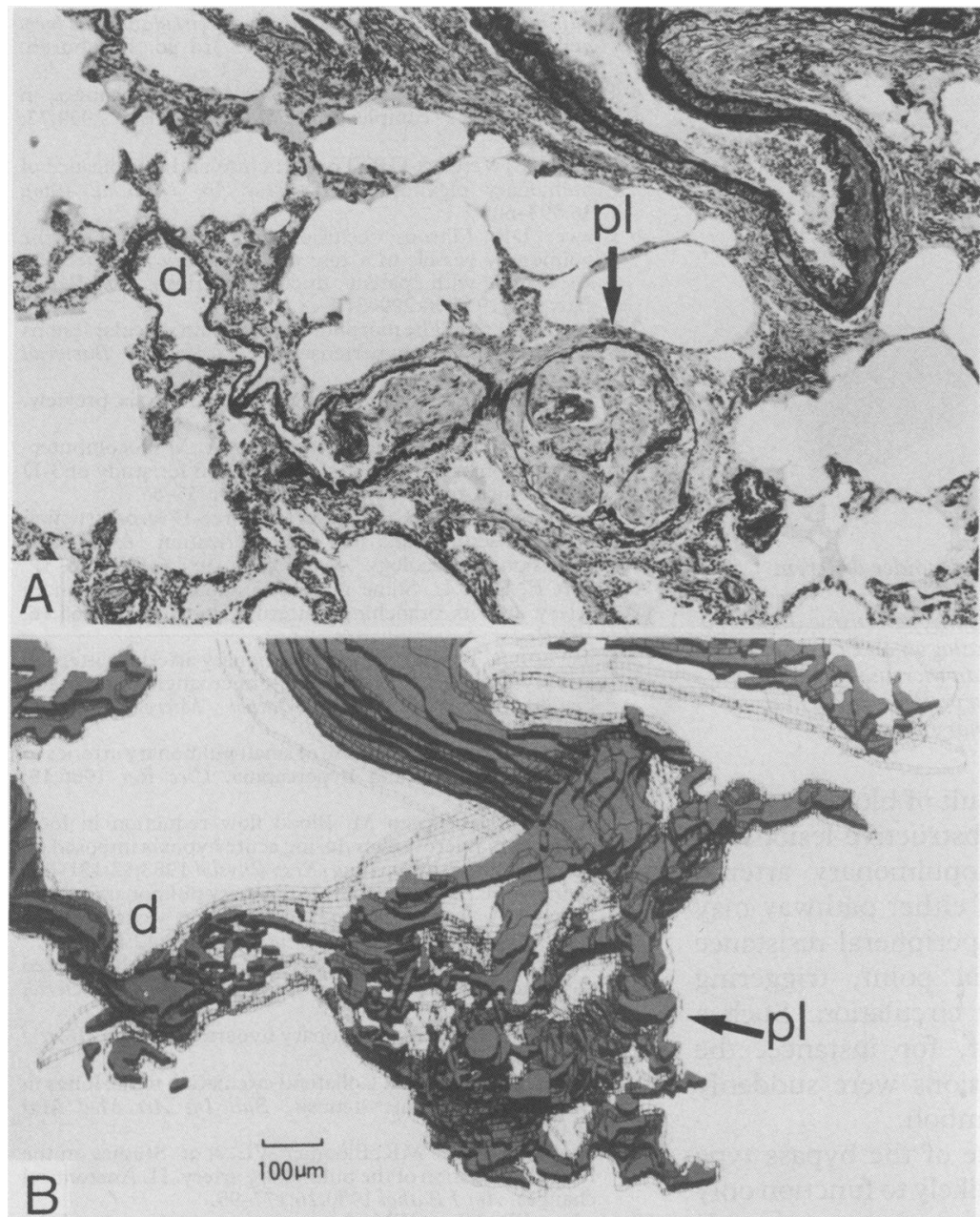

Figure 5 (a) Plexiform lesion ( $p l)$, consisting of a microaneurysmal distension (arrow) with intraluminal proliferation of mesenchymal cells, penetrated by a plexus of channels. A dilatation lesion (d) is present distally. (Elastica-Goldner.) (b)

Reconstruction corresponding to (a) with the outer contours of the arteries shown as lacy ribbons. The distal part of the plexiform lesion communicates with the dilatation lesion.

artery, the number and size of bronchopulmonary anastomoses increase, ${ }^{18-20}$ leading to an increase in systemic supply to the pulmonary capillaries. Bronchopulmonary anastomoses also develop in chronic inflammatory lung disorders such as tuberculosis, abscess, and bronchiectasis, ${ }^{2122}$ and in these patients bronchial arterial flow is also considerably increased. ${ }^{23-25}$ There is, however, no increase in bronchial arterial blood in the pulmonary

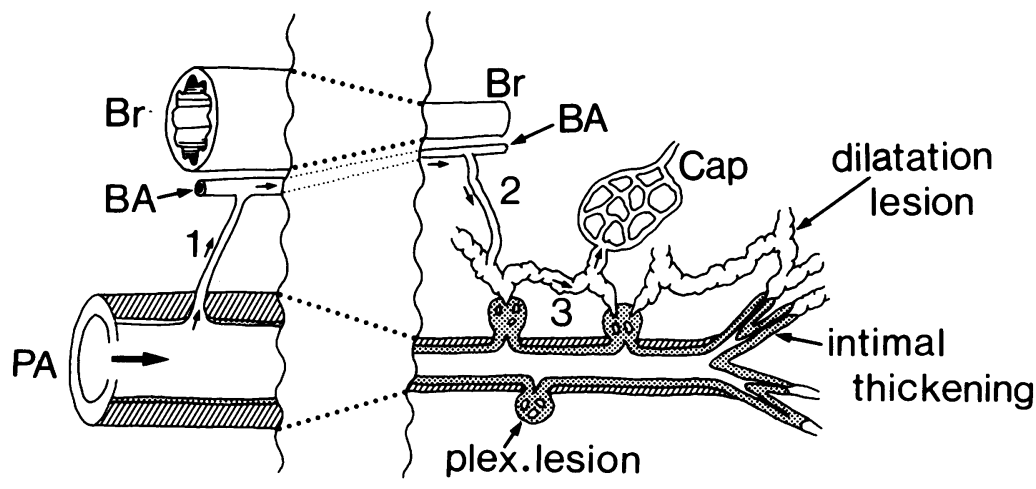

Figure 6 Schematic drawing illustrating the reorganisation of the pulmonary circulation in advanced hypertensive pulmonary vascular disease. Blood reaches alveolar capillaries via small remaining channels in the obstructive lesions or through bypass type collateral vessels by way of bronchial arteries $(B A)$. In the latter blood flows through a proximal bronchopulmonary arterial anastomosis (1), distal bronchopulmonary arterial anastomoses (2), and finally anastomoses among dilatation lesions (3).

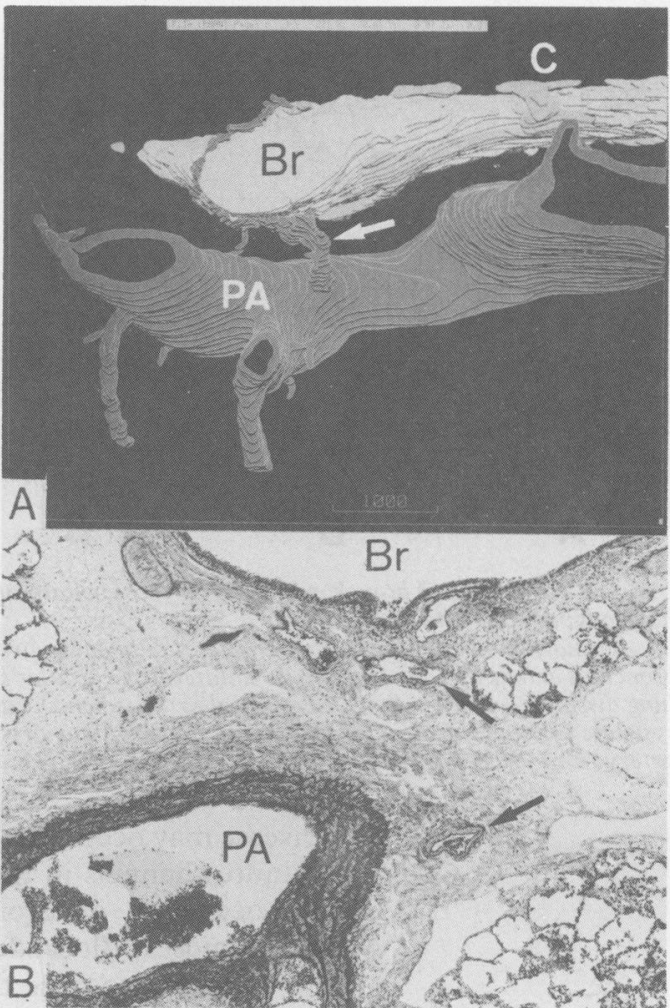

Figure 7 (a) Reconstruction of a proximal

bronchopulmonary arterial anastomosis. $P A$ - pulmonary artery; $\mathrm{Br}$-bronchus; $\mathrm{C}$-cartilage. (b) Section corresponding to $(a)$. The anastomosing artery is indicated by an arrow. (Elastica-Goldner.)

circulation in cases of cardiogenic pulmonary hypertension, despite considerable obstruction of the pulmonary vascular bed.

The results of this study suggest that in the pulmonary hypertension of congenital heart disease the bronchial arteries could function as "bypass type" collateral vessels. Because the pulmonary arterial pressure is high, blood is diverted from pulmonary to bronchial arteries via anastomoses that develop at a proximal, prestenotic site. It then flows through the bronchial arteries to dilatation lesions, and thence to the alveolar capillaries. The inflow of systemic blood is not increased; the bronchial arteries act merely as a bypass route. This haemodynamic pattern differs from that found in conditions of low pulmonary blood flow, such as Fallot's tetralogy, or in chronic inflammatory conditions, where the bronchial arterial pressure exceeds the pulmonary arterial pressure, producing a "compensatory" increase in blood flow (fig 8). Interestingly, in dogs with pulmonary hypertension induced by aortopulmonary anastomosis thin walled vessels, mostly arising from the bronchial arteries, developed to circumvent the obstructed sites in the pulmonary arteries. ${ }^{2627}$ Microangiography, again in dogs with aortopulmonary anastomoses, has also shown collateral vessels between bronchial and pulmonary arteries communicating with the alveolar capillaries, which have been regarded as bronchopulmonary collateral anastomoses. ${ }^{28}$ These vessels seem likely to correspond to the bypass type collaterals described above.

Failure of the pulmonary circulation in patients with advanced pulmonary vascular 


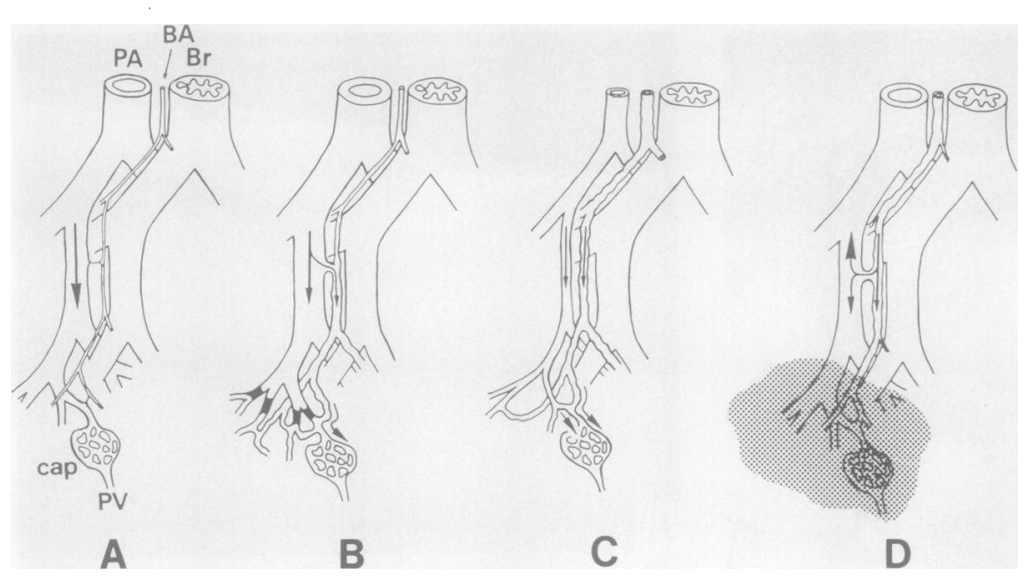

Figure 8 Function of bronchopulmonary bypass collateral vessels under different haemodynamic conditions.

$A$-normal; $B$-obstruction of a peripheral pulmonary artery by hypertensive disease, $a$ bronchial artery serving as a bypass collateral; $C$ (Fallot's tetralogy) and D (chronic lung disease) - proliferation of bronchial arteries, which carry an increased amount of systemic blood to the alveolar capillaries. $P A-$ pulmonary artery; $B A-$ bronchial artery; $B r$-bronchus; cap-alveolar capillaries; $P V$ - pulmonary vein.

disease may occur as a result of blockage of the minute channels in the obstructive lesions, or by occlusion of bronchopulmonary arterial anastomoses. Blockade of either pathway may be sufficient to raise the peripheral resistance beyond a certain critical point, triggering failure of the pulmonary circulation. Such a condition would arise if, for instance, the channels of plexiform lesions were suddenly occluded by thrombi or emboli.

The clinical importance of the bypass type collaterals is that they are likely to function only when the pulmonary artery pressure exceeds that of the bronchial arteries at the level of the proximal anastomoses. If a congenital cardiac shunt is closed when Eisenmenger syndrome is already established, the pressure gradient would be reduced, causing a substantial reduction in collateral flow. In Eisenmenger syndrome therefore the high arterial pressure appears to be a necessary evil.

We would like to thank Dr A Takao, Dr M Ando, Dr Y Imai, Dr H Kurosawa, and Dr A Kajita, Tokyo Women's Medical College, for providing materials. This work was supported by a grant in aid from the Japanese Government Ministry of Education and Culture (No 62480136).

1 Heath D, Edwards JE. The pathology of hypertensive pulmonary vascular disease. A description of six grades of structural changes in the pulmonary arteries with special reference to congenital cardiac septal defects. Circulation 1958;18:533-47.

2 Wagenvoort CA, Wagenvoort N. Pathology of pulmonary hypertension. New York: Wiley, 1977:56-94.
3 Harris $\mathrm{P}$, Heath D. The kuman pulmonary circulation: its form and function in health and disease. 3rd ed. Edinburgh Churchill Livingstone, 1986:247-301.

4 Brewer DB, Heath D. Pulmonary vascular changes in Eisenmenger's complex. J Pathol Bacteriol 1959;77: 141-7.

5 Naeye RL, Vennart GP. The structure and significance of pulmonary plexiform structures. Am J Pathol 1960; 36:593-605.

6 Brewer DB. Fibrous occlusion and anastomosis of the pulmonary vessels in a case of pulmonary hypertension pulmonary vessels in a case of pulmonary hypertension associated with patent

7 Wagenvoort CA. The morphology of certain vascular lesions in pulmonary hypertension. J Pathol Bacteriol 1959;78:503-11.

8 DeHoff RT. Quantitative serial sectioning analysis: preview. J Microscopy 1983;131:259-63.

9 Yaegashi H, Takahashi T, Kawasaki M. Microcomputeraided reconstruction: a system designed for study of 3-D microstructure. J Microscopy 1987;146:55-65.

10 Takahashi T, Chiba T, Yaegashi H. Three-D reconstruction of biostructures and its computerization. A possible of biostructures and its computerization. A possible

11 Elliott F, Reid L. Some new facts about the pulmonary artery and its branching pattern. Clin Radiol 1965;16: 193-8.

12 Robertson $B$. The normal intrapulmonary arterial pattern in infancy and early childhood. A microangiographic and histological study. Acta Pathol Microbiol Scand 1967;71:481-501.

13 Kato M, Staub NC. Response of small pulmonary arteries to unilobar hypoxia and hypercapnia. Circ Res 1966;19: 426-40.

14 Koyama T, Horimoto $M$. Blood flow reduction in local pulmonary microvessels during acute hypoxia imposed on a small fraction of the lung. Resp Physiol 1983;52:181-89.

15 Wagenvoort CA, Wagenvoort N. Primary pulmonary hypertension. A pathologic study of the lung vessels in 156 clinically diagnosed cases. Circulation 1970;42:1163-84.

16 Spencer H. Primary pulmonary hypertension and related vascular changes in the lung. $J$ Pathol Bacteriol 1950;62:75-84

17 Brinton WD. Primary pulmonary hypertension. Br Heart J 1950;12:305-11.

18 Hales MR, Liebow AA. Collateral circulation to the lungs in congenital pulmonic stenosis. Bull Int Ass Med Mus 1948;28:1-11.

19 Liebow AA, Hales MR, Bloomer WE, et al. Studies on the lung after ligation of the pulmonary artery. II. Anatomical lung after ligation of the pulmonary artery
changes. Am J Pathol 1950;26:177-95.

20 Cockett FB, Vass CCN. A comparison of the role of the bronchial arteries in bronchiectasis and in experimental ligation of the pulmonary artery. Thorax 1951;7:268-75.

21 Marchand P, Gilroy JC, Wilson VH. An anatomical study of the bronchial vascular system and its variations in disease. Thorax 1950;5:207-21.

22 Cudkowicz L. The blood supply of the lung in pulmonary tuberculosis. Thorax 1952;14:270-6.

23 Bing RJ, Vandam LD, Gray FD. Physiological studies in congenital heart disease. II. Results of preoperative
studies in patients with tetralogy of Fallot. Bull Johns studies in patients with tetralogy
Hopkins Hosp 1947;80:121-141.

24 Fishman AP, Turino GM, Brandfonbrener M, Himmelstein A. The "effective" pulmonary collateral blood in man. $J$ Clin Invest 1958;37:1071-86.

25 Nakamura T, Katori R, Miyazawa K, Oda J, et al. Bronchial blood flow in patients with chronic pulmonary disease and its influences upon respiration and circulation. Dis Chest 1961;39:193-206.

26 Downing SE, Vidone RA, Brandt HM, Liebow AA. The pathogenesis of vascular lesions in experimental hyperkinetic pulmonary hypertension. Am J Pathol 1963; 43:739-65.

27 Saldana ME, Harley RA, Liebow AA, Carrington CB. Experimental extreme pulmonary hypertension and vas-
cular disease in relation to polycythemia. Am J Pathol cular disease in

28 Friedman PJ. Direct magnification angiography and correlative pathophysiology in experimental pulmonary hypertension. Invest Radiol 1972;7:474-95. 